\title{
Operative therapy of renovascular hypertension
}

\begin{abstract}
Three hundred and thirteen patients exhibiting renal artery occlusive disease underwent operation for renovascular hypertension. These included 34 paediatric and 144 adult patients with fibrodysplastic disease. Atherosclerotic lesions affected an additional 64 patients without and 71 patients with clinically overt extrarenal arteriosclerotic cardiovascular disease. Ischaemic kidney renin hypersecretion (renal: systemic renin index $>0.48$ ), associated with suppressed contralateral kidney renin secretion (renal: systemic renin index approaching 0.0 ), predicted curability most reliably. Four hundred and fifteen operations were performed of which 356 were primary and 59 were secondary procedures. Aortorenal bypass using autogenous vein (227 cases) or prosthetic grafts (62 cases) was the most common primary operation. Nephrectomy was the initial therapy in 17 cases. Six operative deaths occurred in patients manifesting overt extrarenal arteriosclerotic disease. No operative mortality was encountered among the remaining 242 patients. Improvement was seen following operation in 97 per cent of paediatric patients and 94 per cent of adults with fibrodysplastic disease, in 91 per cent of patients with focal renal arteriosclerosis and in 72 per cent of those exhibiting overt extrarenal arteriosclerosis.
\end{abstract}

J. C. STANLEY, W. M.

WHITEHOUSE, L. M. GRAHAM, J. L. CRONENWETT, G. B. ZELENOCK AND S. M. LINDENAUER

Division of Peripheral Vascular Surgery Department of Surgery. University of Michigan Medica! School, Ann Arbor, Michigan, USA

Correspondence to: J. C. Stanley, University Hospital, 1405 East Ann Street. Ann Arbor. Michigan 48109, USA
Occlusive renal artery disease is the most common cause of surgically correctable hypertension. The precise incidence of renovascular hypertension remains poorly defined, yet its clinical importance has been firmly established. Remarkable refinements in the diagnosis and operative treatment of this form of secondary hypertension have occurred during the past decade. This report, an update of an earlier review from our group (1), summarizes the surgical treatment of 313 patients who underwent a total of 415 operations for renovascular hypertension at the University of Michigan Medical Center from 1961 to 1980 .

\section{Patients and methods}

In recognition of the heterogeneity of renovascular hypertension with respect to cause, clinical manifestations and therapeutic results, patients in this series were classified into four subgroups.

I. Paediatric patients with fibrodysplasia.

II. Adults exhibiting renal artery fibrodysplasia

III. Adults with arteriosclerosis-clinical evidence of arteriosclerosis being limited to hypertension as a result of focal renal artery disease.

IV. Adults with renal artery lesions as part of generalized clinically overt arteriosclerotic disease, including extracranial cerebrovascular lesions causing stroke or transient ischaemic attacks, coronary artery disease associated with angina pectoris or myocardial infarction, peripheral arterial occlusive lesions causing symptomatic lower limb ischaemia and aneurysms of the abdominal aorta or its branches (Table n). Excluded from review were hypertensive patients with renal artery emboli, trauma-induced occlusions of dissections and arteriovenous fistulas, as well as those with aneurysmal disease unassociated with blood pressure elevation. Observed differences within these subgroups of hypertensives were analysed by $\chi^{2}$, paired and unpaired Student's $t$ tests.

Paediatric patients (group I) ranged in age from 22 months to 17 years. Renal artery stenoses were of an intimal or atypical medial-perimedial dysplastic type in all but 2 patients who exhibited an inflammatory arteritis. Ostial stenoses, affecting half the patients in this subgroup, were often associated with neurofibromatosis or abdominal aortic developmental anomalies $(2,3)$. Focal stenosis of the main renal artery and isolated segmental disease occurred with near-equal frequency in the remaining patients.

Adults with fibrodysplastic disease (group II) ranged in age from 18 to 64 years. Women were affected 12 times more often than men supporting speculation that oestrogens have an important influence in the pathogenesis of medial dysplastic disease (4). Bilateral renal artery stenoses occurred in nearly 65 per cent of these patients, although functionally significant occlusive lesions were seen in only 15 per cent of these cases. Among adults with dysplastic stenoses, approximately 85 per cent had medial fibrodysplasia, 10 per cent had perimedial dysplasia, a rare patient had medial hyperplasia and the remaining 5 per cent exhibited intimal fibroplasia. No sex predilection was apparent among patients exhibiting intimal disease.

Arteriosclerotic cases were strikingly similar whether associated with focal renal lesions (group III) or overt systemic disease (group IV). Men outnumbered women $2: 1$ in both subgroups. Their ages ranged from 35 to 70 years. Eccentric or concentric proximal renal artery

Table I: RENOVASCULAR HYPERTENSION PATIENT SUBGROUPS: UNIVERSITY OF MICHIGAN 1961-1980

\begin{tabular}{|c|c|c|c|c|c|}
\hline Subgroup & $\begin{array}{l}\text { No. } \\
\text { of } \\
\text { patients } \\
\text { sex }\end{array}$ & $\begin{array}{l}\text { Mean } \\
\text { age } \\
(y r)\end{array}$ & $\begin{array}{c}\text { Duration } \\
\text { of } \\
\text { hypertension } \\
(\mathrm{mth})\end{array}$ & $\begin{array}{l}\text { Preoperative blood } \\
\text { pressure without } \\
\text { drug therapy } \\
\text { (mmHg) }\end{array}$ & $\begin{array}{c}\text { Preoperative blood } \\
\text { pressure with } \\
\text { drug therapy } \\
(\mathrm{mmHg})\end{array}$ \\
\hline $\begin{array}{l}\text { I. Fibrodysplasia } \\
\text { paediatric }\end{array}$ & $\begin{array}{l}19 / \mathrm{M} \\
15 / \mathrm{F}\end{array}$ & $\begin{array}{l}10 \cdot 1 \\
13 \cdot 7\end{array}$ & $11 \cdot 2$ & $175 / 118$ & $162 / 106^{*}$ \\
\hline $\begin{array}{l}\text { II. Fibrodysplasia } \\
\text { adult }\end{array}$ & $\begin{array}{r}133 / \mathrm{F} \\
11 / \mathrm{M}\end{array}$ & $\begin{array}{l}39 \cdot 1 \\
30 \cdot 5\end{array}$ & $42 \cdot 5$ & $206 / 122$ & $184 / 111^{*}$ \\
\hline $\begin{array}{l}\text { I11. Arteriosclerosis } \\
\text { focal renal artery disease }\end{array}$ & $\begin{array}{l}41 / \mathrm{M} \\
23 / \mathrm{F}\end{array}$ & $\begin{array}{l}53 \cdot 4 \\
55 \cdot 1\end{array}$ & 67.5 & $218 / 214$ & $192 / 118+$ \\
\hline $\begin{array}{l}\text { IV. Arteriosclerosis } \\
\text { overt generalized disease }\end{array}$ & $\begin{array}{l}47 / \mathrm{M} \\
24 / \mathrm{F}\end{array}$ & $\begin{array}{l}54 \cdot 1 \\
53 \cdot 3\end{array}$ & $72 \cdot 1$ & $216 / 123$ & $194 / 110^{*}$ \\
\hline
\end{tabular}

See text for definition of subgroup populations.

Differences between preoperative pressures without and with drug therapy, ${ }^{*} P<0 \cdot 01:+P<0.05$ 
stenoses were bilateral in nearly half the cases, with equal involvement of the right and left sides in cases of unilateral arteriosclerotic lesions.

Certain clinical characteristics of renovascular hypertension may distinguish it from essential hypertension, but unfortunately, there are no pathogonomic manifestations of this disease. Marked elevations of blood pressure in paediatric patients, unaccompanied by obvious renal disease, associated with failure to thrive in infants and younger children or hyperkinesis and seizures in older children may herald the presence of renovascular hypertension. Adults with fibrodysplastic disease usually present with a relatively sudden onset of diastolic hypertension exceeding $115 \mathrm{mmHg}$, that is often accompanied by early fatigue and lethargy. Arteriosclerotic renovascular hypertension has similar characteristics but tends to be more refractory to drug therapy. Although significant reductions in blood pressure occurred with drug therapy in all four subgroups, it is noteworthy that no patient had a normal blood pressure at the time of operation. This represents a select population resistant to medical treatment. It should also be recognized that none of these patients was treated with angiotensin I converting enzyme inhibitors. In light of recent experience with these drugs, it is possible that many patients might have had their hypertension controlled by such agents.

\section{Diagnostic evaluation}

Patients whose hypertension was suspected of having a renovascular cause were subjected to a variety of tests early in our study, including, hypertensive urography, renal scans, renograms, split renal function studies, operative assessments of renal artery pressure gradients and renal biopsies. Substantial false-positive and false-negative results limited the value of these studies, and they have been replaced by arteriographic examinations and renin assays.

Rapid sequence intravenous urography deserves special comment. Because of numerous normal urograms in patients with proved renovascular hypertension, such studies are currently considered to have little diagnostic value (5). Although urograms may provide valuable information regarding non-vascular renal disease, positive studies suggesting ischaemia occurred in only 27 per cent of paediatric patients, 48 per cent of adults with fibrodysplastic disease and 72 per cent and 73 per cent of arteriosclerotic patients with focal and clinically overt systemic disease, respectively. These results fail to justify continued use of hypertensive urography as a screening or prognostic test.

Arteriographic studies have proved very useful in assessing the morphological character and haemodynamic importance of occlusive renal artery disease. Demonstration of collateral vessels as a manifestation of a functionally important stenosis has been important in this regard. Recognition of non-parenchymal renal artery branches serving as collateral channels by pharmacoangiographic means using selective intra-arterial adrenaline and acetylcholine has been invaluable in detecting subtle but significant stenoses (6).

Plasma renin assays have been relatively accurate in documenting functionally important renal ischaemia. Renal vein renin ratios (RVRR), comparing renin activity in the effluent from the ischaemic and contralateral kidneys, are considered abnormal when greater than 1.48. Unfortunately, these have not proved to be reliable predictive tests. In our series, 16 per cent of patients benefiting from operation had an RVRR of less than 1.48. In part, this may reflect functionally important bilateral disease or the fact that RVRRs revert towards unity with development of collateral vessels (7). The mean RVRRs in 60 cured and 84 improved patients, being 2.24 and $2 \cdot 15$ respectively, were not significantly different. Thus, as a prognostic test, RVRR had little discriminatory value.

Determination of individual kidney renin secretory activity, expressed as a renal: systemic renin index (RSRI), lessens errors incumbent to renin ratio determinations (8). The RSRI, documenting individual kidney renin hypersecretion or suppression, is calculated by subtracting systemic renin activity from renal vein renin activity, and dividing the remainder by the systemic renin activity. Hypersecretion occurs with an RSRI greater than 0.48 . Suppression exists with an RSRI of less than $0 \cdot 24$, approaching 0.0 . Application of the RSRI data to cured and improved patients in the current series revealed ischaemic kidney hypersecretion in both groups. The mean ischaemic kidney RSRI of 1.19 in 45 cured patients and of 1.23 in 53 improved patients were not statistically different. Importantly, nearly complete contralateral suppression to an RSRI of 0.04 occurred in cured patients. This proved significantly less $(P<0.01)$ than the mean RSRI of 0.32 observed among improved patients. Thus, patients most likely to be cured from unilateral operation are those exhibiting renin hypersecretion from the affected kidney, and suppressed renin production from the opposite kidney. Absolute and relative renin activities did not appear to vary among the various subgroups of renovascular hypertension.

RVRR and RSRI data that are difficult to interpret may arise from minor variations in absolute renin secretion when samplings are performed under basal conditions. Mathematical comparisons in the form of RVRR or RSRI tend to magnify minimal differences that occur when absolute renin production is small. To lessen such errors, $i$ is our current practice in adults to stimulate the renin-angiotensin system by reducing sodium intake to $20 \mathrm{mmol} /$ day while administering a natriuretic drug for 3 days preceding sampling. Specimens are obtained near simultaneously with patients tilted in an upright position. Radioimmunoassay techniques (angiotensin I) are used to assay renin activity.

Operative therapy

A total of 415 surgical procedures were performed: there were 356 primary operations (Table $I I$ ), of which 38 were for bilateral disease, and 59 secondary operations. Certain principles have evolved in our surgical management of these patients, including:

1. Transabdominal approach to the renal artery and aorta by reflection of the colon, duodenum and related structures medially, thus facilitating an unencumbered exposure of the retroperitoneum.

2. Systemic anticoagulation with heparin sodium (150 units $/ \mathrm{kg}$ ) before renal artery clamping.

3. Preferred revascularization using an autogenous saphenous vein aortorenal bypass with end-to-end, graft-to-renal artery anastomoses

4. Spatulation of vessels to be anastomosed, thereby increasing the suture line circumference and lessening the potential for late stricture formation.

5. Utmost care in handling all tissues and patients during the first operation, with a realization that greater efforts and fewer benefits attend reoperation.

Most common of primary operations were 277 autogenous saphenous vein reconstructions, usually in the form of aortorenal bypasses. This has been our favoured method of renal revascularization in adults with fibrodysplastic and focal arteriosclerotic renal artery disease. Parenthetically, of 8 aneurysmal vein grafts documented in 474 postoperative arteriographic studies in this series, 6 occurred in the paediatric age group. Because of this, hypogastric arterial aortorenal

Table II: PRIMARY OPERATIONS FOR RENOVASCULAR HYPERTENSION: UNIVERSITY OF MICHIGAN 1961-1980

\begin{tabular}{lcccc}
\hline \multicolumn{1}{c}{ Subgroup } & $\begin{array}{c}\text { Autogenous } \\
\text { saphenous vein } \\
\text { reconstruction }\end{array}$ & $\begin{array}{c}\text { Prosthetic } \\
\text { graft } \\
\text { reconstruction }\end{array}$ & Other & Nephrectomy \\
\hline $\begin{array}{l}\text { I. Fibrodysplasia } \\
\begin{array}{l}\text { paediatric } \\
\text { II. Fibrodysplasia }\end{array}\end{array}$ & 28 & 0 & 11 & 2 \\
$\begin{array}{l}\text { adult } \\
\text { III. Arteriosclerosis } \\
\text { focal renal artery } \\
\text { disease }\end{array}$ & 129 & 12 & 19 & 6 \\
$\begin{array}{l}\text { IV. Arteriosclerosis } \\
\text { overt generalized } \\
\text { disease }\end{array}$ & 43 & 13 & 10 & 3 \\
\hline
\end{tabular}

See text for definition of subgroup populations.

Other operations encompass resections with re-anastomoses or aortic reimplantation, endarterectomy,

local arterioplasty, operative dilatation and autogenous artery reconstructions.

Ten of the 17 primary nephrectomies were for advanced parenchymal disease. 
Table III: OPERATIVE TREATMENT OF RENOVASCULAR HYPERTENSION: RESULTS IN SPECIFIC PATIENT SUBGROUPS AT UNIVERSITY OF MICHIGAN 1961-1980

\begin{tabular}{|c|c|c|c|c|c|}
\hline \multirow[b]{2}{*}{ Subgroup } & \multirow{2}{*}{$\begin{array}{c}\text { No. } \\
\text { of } \\
\text { patients }\end{array}$} & \multicolumn{3}{|c|}{ Postoperative status } & \multirow{2}{*}{$\begin{array}{l}\text { Operative } \\
\text { mortality }\end{array}$} \\
\hline & & Cured & Improved & Failure & \\
\hline $\begin{array}{l}\text { I. Fibrodysplasia } \\
\text { paediatric }\end{array}$ & 34 & $29(85 \%)$ & $4(12 \%)$ & $1(3 \%)$ & $0\left(0_{\%}^{\circ}\right)$ \\
\hline $\begin{array}{l}\text { II. Fibrodysplasia } \\
\text { adult }\end{array}$ & 144 & $79(55 \%)$ & $56(39 \%)$ & $9\left(6_{\%}^{\circ}\right)$ & $0\left(0^{\circ} \%\right)$ \\
\hline $\begin{array}{l}\text { III. Arteriosclerosis } \\
\text { focal renal artery } \\
\text { disease }\end{array}$ & 64 & $21(33 \%)$ & $37(58 \%)$ & $6(9 \%)$ & $0(0 \%)$ \\
\hline $\begin{array}{l}\text { IV. Arteriosclerosis } \\
\text { overt generalized } \\
\text { disease }\end{array}$ & 71 & $18(25 \%)$ & $33(47 \%)$ & $20(28 \%)$ & $6(8 \cdot 5 \%)$ \\
\hline
\end{tabular}

See text for definition of subgroup populations

Operative mortality includes death within 30 days of procedure. Four of 6 deaths occurred in patients undergoing concomitant aortic reconstructive surgery.

grafts are preferred for reconstructions in paediatric patients. Prosthetic Dacron velour grafts were used most often when undertaking renal revascularizations in association with reconstructions of the aorta for occlusive or aneurysmal disease. Less common procedures accounted for nearly a quarter of the primary operations, and included local arterioplasty, resection and re-anastomosis or aortic reimplantation of the renal artery, as well as operative dilatation. Primary nephrectomies were performed on 17 occasions, including 10 instances when such was undertaken for advanced parenchymal disease thought to be too severe to justify attempted revascularization

Secondary operations were performed 59 times in 43 patients, including revisions with autogenous vein and prosthetic grafts in 12 cases each, a variety of other procedures an additional 12 times, and nephrectomy in 23 patients. Since technical difficulties of reoperation often result in loss of a kidney (9), it is evident that greater attention must be directed to the initial vascular reconstruction.

\section{Results}

The effectiveness of operative intervention was based on blood pressure status at the time of most recent follow-up examination (Table III). Responses were categorized by carefully defined criteria. Patients were considered cured if their blood pressures were $150 / 90 \mathrm{mmHg}$ or less for a minimum of 6 months, during which time no antihypertensive drugs were administered. Lower pressure levels were utilized in evaluating paediatric cases. Patients were considered improved if normotensive while on drug therapy, or if diastolic pressures ranged between 90 and $110 \mathrm{mmHg}$ but were at least 15 per cent lower than preoperative levels. None of the patients in this category were on angiotensin I converting enzyme inhibitors. If diastolic blood pressures were greater than $90 \mathrm{~mm} \mathrm{Hg}$ but less than 15 per cent lower than preoperative levels, patients were classified as failures. Similarly, all patients with diastolic blood pressures greater than $110 \mathrm{mmHg}$ were included in the latter group.

Paediatric patients exhibited the greatest cure rate- 85 per cent. This response decreased to 55 per cent in adults with fibrodysplastic disease and to 33 per cent and 25 per cent among arteriosclerotic patients with focal and clinically overt systemic disease, respectively. If one combines patients in the cured and improved categories, then 97 per cent of the paediatric population, 94 per cent of the adult fibrodysplasia group and 91 per cent of the adult arteriosclerotics with focal disease benefited from operation. Although 72 per cent of patients with clinically overt generalized atherosclerosis also benefited from operation, this was associated with an 8.5 per cent operative mortality rate ( 6 deaths). These deaths occurred in azotaemic patients or were associated with concomitant aortic reconstructive surgery in all but 1 case. No operative deaths occurred in the remaining 242 patients with renovascular hypertension unaccompanied by clinically overt arteriosclerosis.

Duration of preoperative hypertension did not correlate with eventual benefits of surgical therapy and there was no statistical difference in the incidence of hypertension between patients followed for less than 60 months postoperatively (50 per cent cured, 41 per cent improved and 9 per cent treatment failures) and those followed for more than 60 months postoperatively
( 45 per cent cured, 45 per cent improved and 10 per cent treatment failures). Improved renal function was an uncommon and unexpected outcome of renal revascularization, occurring most often when treating patients with totally occluded renal arteries (10). The fact that late mortality in patients with clinically overt systemic atherosclerosis was twice as great as in those with focal renal artery disease, supports the contention that renovascular hypertension in this subgroup does not carry the same ominous prognosis attending clinically overt extrarenal arteriosclerotic cardiovascular disease.

\section{Discussion}

Operative therapy of renovascular hypertension is preferred to medical treatment in properly selected patients. Arterial reconstructions are favoured in all paediatric patients and young adults. Similarly, it appears advantageous to pursue surgical therapy in older patients with either fibrodysplastic or focal renal artery arteriosclerotic disease when medical management of their hypertension becomes difficult. Surgical therapy of renovascular hypertension associated with clinically overt generalized arteriosclerotic cardiovascular disease is more controversial. Operative therapy is most appropriate in such patients, who are non-responsive or intolerant to intensive drug therapy or who exhibit a documented deterioration in renal function.

The excellent results of operative therapy evident in this report are remarkably similar to outcomes recently encountered at other centres treating large numbers of renovascular hypertensives. Alternatives to surgical treatment, such as drug therapy with new angiotensin I converting enzyme inhibitors or percutaneous transluminal angioplasty, must be judged in the light of contemporary long term operative results. Beneficial responses to surgical intervention should be expected in 90-95 per cent of patients with renovascular hypertension These results represent standards of contemporary practice which reflect two important determinants of successful treatment an accurate diagnosis and a properly executed operation.

\section{References}

1. Stanley J. C. and Fry W. J.: Surgical treatment of renovascular hypertension. Arch. Surg. 1977; 112: 1291-7.

2. Stanley J. C. and Fry W. J.: Pediatric renal artery occlusive disease and renovascular hypertension. Etiology, diagnosis and operative treatment. Arch. Surg. 1981; 116: 669-76.

3. Stanley J. C., Graham L. M., Whitehouse W. M. et al.: Develop mental occlusive disease of the abdominal aorta, splanchnic and renal arteries. Am. J. Surg. 1981; 142: 190-6.

4. Stanley J. C. Gewertz B. L. Bove E. L. et al: Arterial fibrodysplasia. Histopathologic character and current etiologic concepts. Arch. Surg. 1975; 110: 561-6.

5. Thornbury J. R., Stanley J. C. and Fryback D. G.: Hypertensive urogram: a nondiscriminatory test for renovascular hypertension. Am. J. Roentgenol. 1982; 138: 43-9.

6. Bookstein J. J., Walter J. F., Stanley J. C. et al.: Pharmacoangiographic manipulation of renal collateral blood flow. Circulation 1976: 54: 324-34. 
7. Ernst C. B., Bookstein J. J., Montie J. et al.: Renal vein renin ratios and collateral vessels in renovascular hypertension. Arch Surg. 1972; 104: 496-502.

8. Stanley J. C., Gewertz B. L. and Fry W. J.: Renal : systemic renin indices and renal vein renin ratios as prognostic indicators in remedial renovascular hypertension. J. Surg. Res. 1976: 20: 149-55.
9. Stanley J. C., Whitehouse W. M. and Graham L. M.: Complications of renal revascularization. In: Bernhard V. M. and Towne J. B. (ed.) Complications of Vascular Surgery. New York: Grune

10. Whitehouse W. M., Kazmers A.. Zelenock G. B. et al.: Chronic total renal artery occlusion: effects of treatment on secondary hypertension and renal function. Surgery 1981; 89: 753-63. 